\title{
Türkiye'nin Akdeniz Bölgesi için Açık Deniz Enerji Potansiyelinin Değerlendirilmesi ve Bölgesel Sera Gazı Emisyonunlarının Azaltılmasına Etkisi
}

\author{
Ozan Akdağ ${ }^{1 *}$ \\ 1* İnönü Üniversitesi, Mühendislik Fakültesi, Bilgisayar Mühendisliği Bölümü, Malatya, Türkiye, (ORCID: 0000-0001-8163-8898), ozanakdag@live.com
}

(2nd International Conference on Access to Recent Advances in Engineering and Digitalization (ARACONF)-10-12 March 2021)

(DOI: 10.31590/ejosat.901251)

ATIF/REFERENCE: Akdağ, O., (2021). Türkiye'nin Akdeniz Bölgesi için Açık Deniz Enerji Potansiyelinin Değerlendirilmesi ve Bölgesel Sera Gazı Emisyonunlarının Azaltılmasına Etkisi. Avrupa Bilim ve Teknoloji Dergisi, (24), 343-350.

\section{$\ddot{O} \mathbf{z}$}

Yenilenebilir enerji, dünya genelinde çevre dostu olması nedeniyle elektrik üretimindeki payını sürekli olarak artırmaktadır. Bu makale, Türkiye'nin yenilenebilir enerjiden daha fazla yararlanmasını sağlayarak, sera ve zehirli gaz emisyonlarının azaltılmasına katkıda bulunmayı amaçlamaktadır. Bu çalışmada ilk olarak Türkiye ve dünyadaki mevcut sera gazı emisyonlarının azaltılmasına yönelik politikalar incelenmiştir. Devamında, Türkiye'nin ilgili bölgesinde Açık Deniz Rüzgâr Santrali (ADRS) kurulum kriterlerine göre uygun lokasyonlar belirlenmiş ve bu lokasyonların meteorolojik verileri Rüzgâr Atlası analiz / uygulama programında (WaSP) analiz edilerek en iyi lokasyonun bulunması sağlanmıştır. Daha sonra en iyi lokasyon belirlendikten sonra, ADRS ve bölgesel güç sisteminin sanal modelleri DigSilent yazılımı kullanılarak modellenmiştir. Ardından, bu modelde yük akış analizi gerçekleştirilmiş ve elde edilem sonuçlar ile önerilen ADRS'nin ana şebekeye bağlanması durumunda bölgede 12300 ton zehirli gaz ve 2,47 milyon ton sera gazının bir yıl içinde azaltılabileceği gösterilmiş̧ir.

Anahtar Kelimeler: Açık deniz rüzgâr santrali, sera gazı emisyonu, yeşil enerji

\section{Evaluation of Offshore Energy Potential for Turkey's Mediterranean Coast and Impact on Reduction of Regional Greenhouse Gas Emissions}

\begin{abstract}
Renewable energy sources have continuously increased their share and installed power in electricity generation in recent years, as they are green energy. This study, by increasing renewable energy capacity of Turkey also aims to contribute to reducing emis sions of greenhouse gases/toxic gases. This paper first, Turkey and in the world studies available for the reduction of greenhouse gas emissions are discussed. Later, suitable locations were determined according to the Offshore Wind Farm (ADRS) installation criteria (for Turkey). Afterwards, meteorological data of these locations were analyzed with WaSP and the best location was found. After determining the best location, the virtual models of OWF and regional transmission system are modeled using DigSilent program. Load flow analysis was carried out using this model. The load flow results are showed that the proposed OWF could reduce 12300 tons of toxic gas and 2.48 million tons of greenhouse gas in one year in the region.
\end{abstract}

Keywords: Offshore Power Plant, greenhouse emissions, green energy

*Sorumlu Yazar: ozanakdag@ live.com 


\section{Giriş}

Literatürde sera etkisi üzerine bilinen ilk çalışma 1827'de Josepf Fourier tarafindan yapılmıştır (Fleming, 1999). Atmosferdeki CO2 nedeniyle iklimin değişikliği olasılığı ise ilk olarak 1896'da Nobel Ödüllü Arrhenius tarafindan rapor edilmiştir (Arrhenius, 1896). Sera etkisi, günümüzün en büyük küresel sorunlarından biridir. Özellikle günümüzde sanayileşme, kentleşme ve artan nüfusun etkisiyle atmosferdeki sera gazı tehlikeli seviyelere ulaşmıştır. Günümüzde büyük oranda elektrik üretiminde kullanılan fosil bazlı termik santraller, atmosferdeki sera gazlarının üçte ikisinden sorumludur (Argin ve Yerci 2017). Fosil bazlı termik santraller SOx, NOx, CO, $\mathrm{CO} 2$ gibi gazlar yayarak dünyamızı kirletmektedir. Bu termik santrallerin çıkardığ 1 gazlardan olan SOx ve NOx gazları, insan ve diğer canlılar üzerinde zehirleyici bir etkiye sahiptir. Bu gazlardan biri olan $\mathrm{CO} 2$ ise büyük bir sera gazı etkisine neden olmaktadır (Bal 2019; Mohsenipour vd. 2020; Benavides vd. 2020). Bu nedenle, son y1llarda geleneksel kömür santrallerinin emisyon seviyesini azaltma çabaları artmıştır (Bal 2019). Bu durum uzun vadede çözüm sunamayacağı için yenilenebilir enerjiye dayalı santraller dünya çapında popüler hale gelmiştir. Yenilenebilir enerji santralleri, sera gazı emisyonlarının azaltılmasında ve iklim değişikliğinin üstesinden gelmede önemli bir rol oynamaktadır. 2018 sonunda, yenilenebilir enerji kaynakları dünya genelinde 2017'ye göre \% 4 büyümüştür (Uluslararası Enerji Ajans1 2018). Yenilenebilir enerji üretimi, özellikle son 10 yılda dünya çapında önemli ölçüde artmıştır (Uluslararası Enerji Ajans1, 2018).

Yenilenebilir enerji kaynaklarından biri olan rüzgâr enerjisi, çevreci oluşu ve teknolojisindeki olumlu gelişmelerden dolayı son 10 y1lda önemli gelişmeler kaydetmiştir. Dünya Rüzgâr Enerjisi Derneği tarafindan 2019 yılında yayınlanan bir rapora göre, kara rüzgâr enerjisi 2018'de 46,8 GW artarak dünya genelinde 568 GW'a ulaşırken, açık deniz rüzgâr enerjisi 2018'de 4,481 GW artarak dünya genelinde 23,2 GW'a ulaşmıştır (WWEA, 2019). Deniz üstü alanların karadan daha verimli olması ve açık deniz rüzgâr teknolojisindeki maliyetlerin azalması nedeniyle açık deniz rüzgâr santrallerinde dünya çapında hızla büyüyor. Ayrıca açık deniz rüzgâr santralleri, kara rüzgâr santrallerine göre daha büyük kurulu güç kapasitesinde kurulduldukları için küresel sera gazı emisyonlarının azaltılmasında önemli bir rol oynamaktadır (Wang vd. 2019). Bu nedenle, açık deniz rüzgar çiftliklerinin potansiyelini araştırmak ve mevcut ağları entegre etmek, dünyanın geleceği için önemlidir.

$\mathrm{Bu}$ çalışma, uygun bir ADRS'nin kurulum, modelleme aşamalarını sunarak küresel sera gazlarının azaltılmasına yönelik araştırmalara katkıda bulunmayı amaçlamaktadır. Bu çalışmada öncelikle ilgili lokasyonlar (ADRS kurulumuna uygun), ADRS kurulum kriterlerine göre değerlendirilerek, belirlenmiştir. Daha sonra belirlenen bu lokasyonların, Türkiye Meteoroloji Genel Müdürlüğünden alınan meteorolojik verileri, rüzgâr enerjisi potansiyelini belirlemek için WAsP yazılımı kullanılarak analiz edilmiştir. Analiz sonucunda ADRS kurulumu için en uygun bölge belirlenerek, devamında bu ADRS ve bölgesel iletim sisteminin bir kesiti DigSilent Power Factory yazılımı kullanılarak modellenmiştir. $\mathrm{Bu}$ modelde yapılan yük akış analizi ile modellenen ADRS ile bölgedeki termik santral faaliyetlerinin azaltılması hedeflenerek, yıllık ne kadar sera gazı ve zehirli gaz emisyonunun azaltılacağı tespit edilmiştir.

\section{Materyal ve Metot}

\subsection{Türkiye'de sera gazı emisyonları ve yenilenebilir enerji kullanımı}

Türkiye'nin kurulu elektrik kapasitesi her yıl yaklaşık \% 4-7 büyüyor. Türkiye'nin kurulu elektrik kapasitesi Aralık 2020'de 95 GW'a ulaşmıştır. Fosil yakıta dayalı elektrik üretim tesisleri, bu kurulu gücün yaklaşık \% 18-25'ine tekabül etmektedir. Türkiye'nin günlük elektriğinin yaklaşık \% 35-45'1 fosil yakıta dayalı elektrik üretimi ile üretilmektedir (Teias 2020). Bu durum, Türkiye'nin küresel sera gazı emisyonlarına önemli katkı sağladığını göstermektedir. 2000'li yılların başında Türkiye, sera gazı emisyonlarının azaltılmasına yönelik politikalar uygulamaya başlamıştır. $\mathrm{Bu}$ konuda en önemli gelişme, Türkiye'nin 2009'da Kyoto Protokolü'ne taraf olmasidır (Erdoğdu 2019). Türkiye, bu protokolle sera gazı emisyonlarını azaltmayı kabul etmiştir. Türkiye, 2010-20 döneminde Ulusal İklim Değişikliği stratejisini açıklayarak iklim değişikliği konusunda önemli adımlar atmıştır (Akyüz ve Atis 2016). Türkiye, özellikle son yıllarda bu politikalarla rüzgâr enerjisinde önemli bir büyüme kaydetmiştir. 2020 yılı itibarıyla Türkiye'nin toplam kurulu rüzgar enerjisi kapasitesi 8.5 GW'a ulaşmıştır. Türkiye kara rüzgâr santrali kurulumunda hızla büyümesine rağmen, Türkiye'de halen kurulu açık deniz santrali bulunmamaktadır. Türkiye'nin 3 tarafının denizlerle çevrili olması, elverişli deniz yapısı ve uzun/düzgün sahil şeridi ile önemli açık deniz rüzgâr potansiyeline sahiptir. Türkiye, deniz derinliği 50 metreden az olan bölgelerde 10-12 GW açık deniz rüzgâr enerjisi potansiyeline sahipken, açık deniz rüzgâr enerjisi potansiyelinin 50-100 metre deniz derinliğine sahip bölgelerde 20-57 GW olduğu düşünülmektedir (Cali ve diğerleri 2018). Bu nedenle, Türkiye'deki açık deniz rüzgâr potansiyeli ile ilgili çalışmalar, küresel sera gazı emisyonlarının azaltılmasına katkı sağlayabilir.

\subsection{ADRS kurulumunda dikkate alınacak hususlar}

Rüzgâr fizibilite çalışması ve konum tespiti ADRS kurulumu için çok önemlidir. ADRS kurulumunda şu hususlar dikkate alınır, - Rüzgâr atlas haritasına göre bölge seçimi, Deniz derinliği ve deniz tabanının genel yapısı, - Askeri ve ulusal sınırlar, - Deniz ulaşım hatları, - Kıta sahanlığı, - Sivil havacılığa ait bölgeler, -Boru hatları ve yer altı kablolarının yakın mesafeleri, -Sosyal ve çevresel faktörler (kentleşme, turizm vb.) (Akdag ve Yeroglu 2020).

\subsection{ADRS kurulum aşamaları}

$\mathrm{Bu}$ yayın, ADRS'yi mevcut bir şebekeye eklemek ve bu ADRS'nin mevcut şebeke ve çevre üzerindeki etkilerini analiz etmek için sanal bir model sunmaktadır. Bu sanal model, mevcut şebekelerde bulunan termik santraller tarafından yayılan sera gazlarının azaltılma miktarını hesaplamak için yük akışının 
sonuçlarını analiz etmektedir. $\mathrm{Bu}$ çalışmada sunulan metot aşağıdaki gibi sunulmuştur;

Adım 1-) ADRS kurulumu için saha seçimi: Rüzgâr potansiyeli ve yer tespiti ADRS kurulumu için çok önemlidir. Bölüm 2.2'de verilen ADRS kurulum kriterlerine göre, ADRS kurulumu için uygun yerler belirlenir. Örneğin ADRS kurulumunda Şekil 1'de gösterilen sınırlı askeri alan ve Şekil 2'de verilen 100 metredeki rüzgâr gücü yoğunluk haritası dikkate alınan bazı verilerdir.

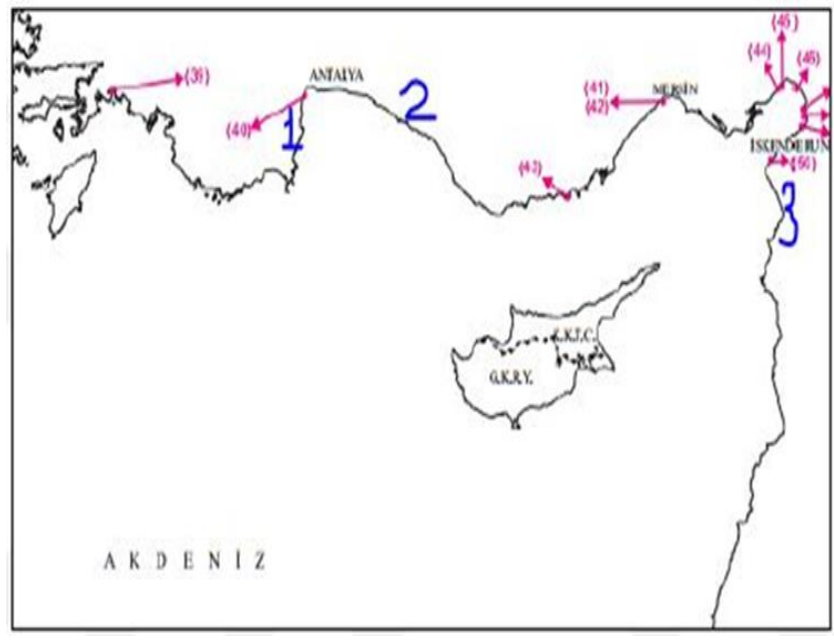
2019)

Şekil 1. Akdeniz Bölgesi Askeri Kısıtlı Alanlar (Marina

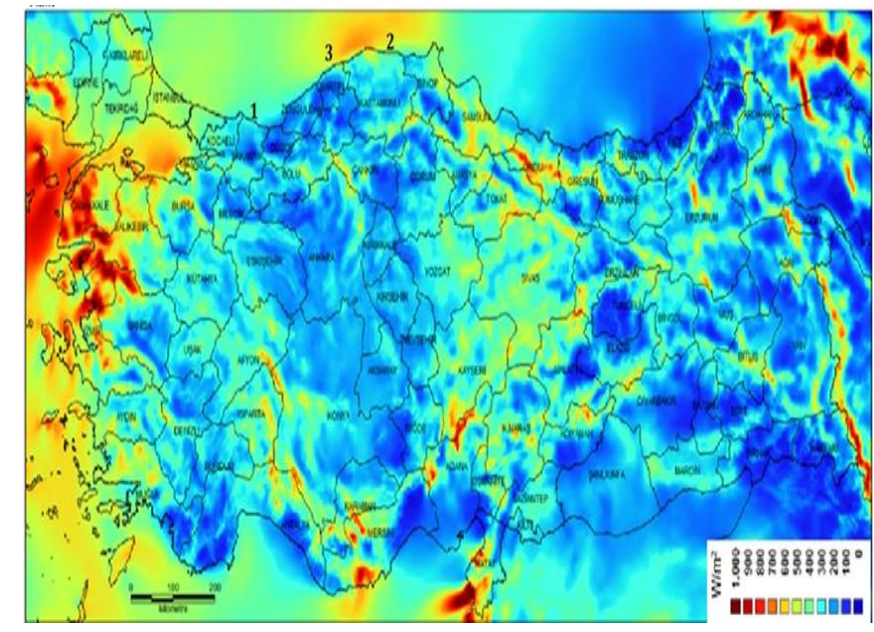

Şekil 2. 100 metrede rüzgâr enerjisi yoğunluk haritası (Türkiye) (Rüzgâr Haritası, 2019)

Adım 2-) İstatistiksel Rüzgâr Potansiyeli Analizi: WAsP yazılımında, Adım 1 ile belirlenen ilgili lokasyonlarda açık deniz rüzgâr potansiyelini belirlemek için İstatistiksel Rüzgâr Potansiyeli Analizi yapılır. Literatürde genel olarak açık deniz rüzgâr potansiyeli değerlendirilirken 100 metre yükseklikte rüzgâr hızı dikkate alınır (Bilgili vd. 2011). Bu nedenle, 100 metre yükseklikte rüzgâr hızı (WAsP yazılımında meteoroloji istasyonunun yüksekliği hesaba katıldığı için) [m/s] literatürde belirtilen Denklem 1 ile hesaplanır (Bilgili vd 2011):

$$
V_{h}=V_{\text {ref }}\left(\frac{h}{h_{\text {ref }}}\right)^{\mu}
$$

burada, $V_{\text {ref }}[\mathrm{m} / \mathrm{s}] 100$ metrede rüzgar hızı; $h[\mathrm{~m}] \boldsymbol{V}_{\boldsymbol{h}}[\mathrm{m} / \mathrm{s}]$ 'e karşılık gelen yükseklik; $h_{r e f}$ [m] 100 metre; $\mu$ pürüzlülük katsayıs1.

Rüzgâr türbini seçimi, rüzgâr hızı ve rüzgâr gücü yoğunluğuna göre belirlenir. Rüzgâr türbininin temel yapısı ise denizin derinliğine, zemin yapısına ve kimyasal yapısına göre belirlenir. Rüzgâr türbini ve temeli seçildikten sonra ilgili lokasyonda uluslararası standartlara göre rüzgâr türbini yerleştirme süreci başlatılır. $\mathrm{Bu}$ süreçten sonra ADRS'nin tahmini kurulu güç kapasitesi ilgili bölgede belirlenir.

Adım c-) Modelleme: ADRS'nin çevre ve termik santral dâhil mevcut şebeke üzerindeki etkilerini analiz etmek için, ADRS ile bölgesel enerji iletim sistemi güç sistemleri yazılım programı kullanılarak (Bu çalışmada DigSilent programı kullanılmıştır) modellenir. Daha sonra bu modelde Newton Raphson yöntemi ile yük akış analizi yapılır. Yük akış analizi sonucunda termik santralin aktif güç üretimi ile termik santralin 1 saat içinde atmosfere yayacağı zehirli ve sera gazı miktarı Denklem 2 ile bulunur (Akdag ve Yeroglu, 2020).

Toplam emisyon $($ ton $/ \mathrm{h})=\sum_{i=1}^{1}\left(\left(a_{i}+\beta_{i} \mathrm{P}_{\mathrm{Gi}}+\right.\right.$ $\left.\left.\gamma_{i} P_{G i}^{2}\right) 10^{-2}+\xi_{i} \exp \left(\lambda_{i} P_{G i}\right)+\quad \epsilon_{\mathrm{i}} P_{G i}\right)($ ton $/ \mathrm{s})$

burada, $a_{i}, \beta_{\mathrm{i}}, \gamma_{\mathrm{i}}, \lambda_{\mathrm{i}}$, i.nci termik santralin emisyon katsayılarıdır, burada $\gamma_{\mathrm{i}}$ (1 / MW2), $\beta_{\mathrm{i}}$ (1 / MW), $a_{i}$ SOx ait iken ve $\xi_{i}, \quad \lambda_{i}(1 / \mathrm{MW})$ NOx'e aittir. $\mathrm{P}_{\mathrm{Gi}},(\mathrm{MW})$ termik santralin santralinin aktif güç üretimine karşılık gelirken, $\mu_{\mathbf{i}}(1 / \mathrm{MW})$ $\mathrm{CO}_{2}$ emisyon katsayıdır (Akdag ve Yeroglu, 2020).

\section{Araştırma Sonuçları ve Tartışma}

\subsection{Akdeniz bölgesinde ADRS kurulumu için uygun konumların açı deniz rüzgâr potansiyelinin değerlendirilmesi}

Bu çalışmada, kıta sahanlığı, uygun deniz yapısı / rüzgâr potansiyeli ve özellikle bölgenin doğusunda yoğun termik santral faaliyetleri nedeniyle ADRS kurulumu için Akdeniz bölgesi seçilmiştir. Bu bölgede, 1. adımında verilen yer seçim kriterlerine göre ADRS kurulumu için 3 uygun lokasyon belirlenmiştir. $\mathrm{Bu}$ lokasyonlar sırasıyla Konyaaltı, Alanya ve Samandağ'dır. Bu lokasyonlara ait meteoroloji istasyonlarının konumları Şekil 3 'te verilmiştir. Şekil 3 'te gösterilen 3 lokasyona ait deniz meteoroloji istasyonlarının 2013-2015 rüzgâr verileri kullanılmıştır (Türkiye Devlet Meteoroloji Kurumu, 2019). Ardından, bu konumların rüzgâr enerjisi potansiyelini belirlemek için WAsP yazılımı kullanılarak istatistiksel analiz yapılır (Adım 1). İstatistiksel analiz sonuçları Tablo 1'de verildiği gibidir. Daha sonra bu konumların 100 metrede rüzgâr hıları (ADRS kurulumunda 100 metredeki rüzgâr hızı esas alındığından) Denklem 2 kullanılarak hesaplanır. 100 metredeki sonuçlar Tablo 2'de verilmiştir. 


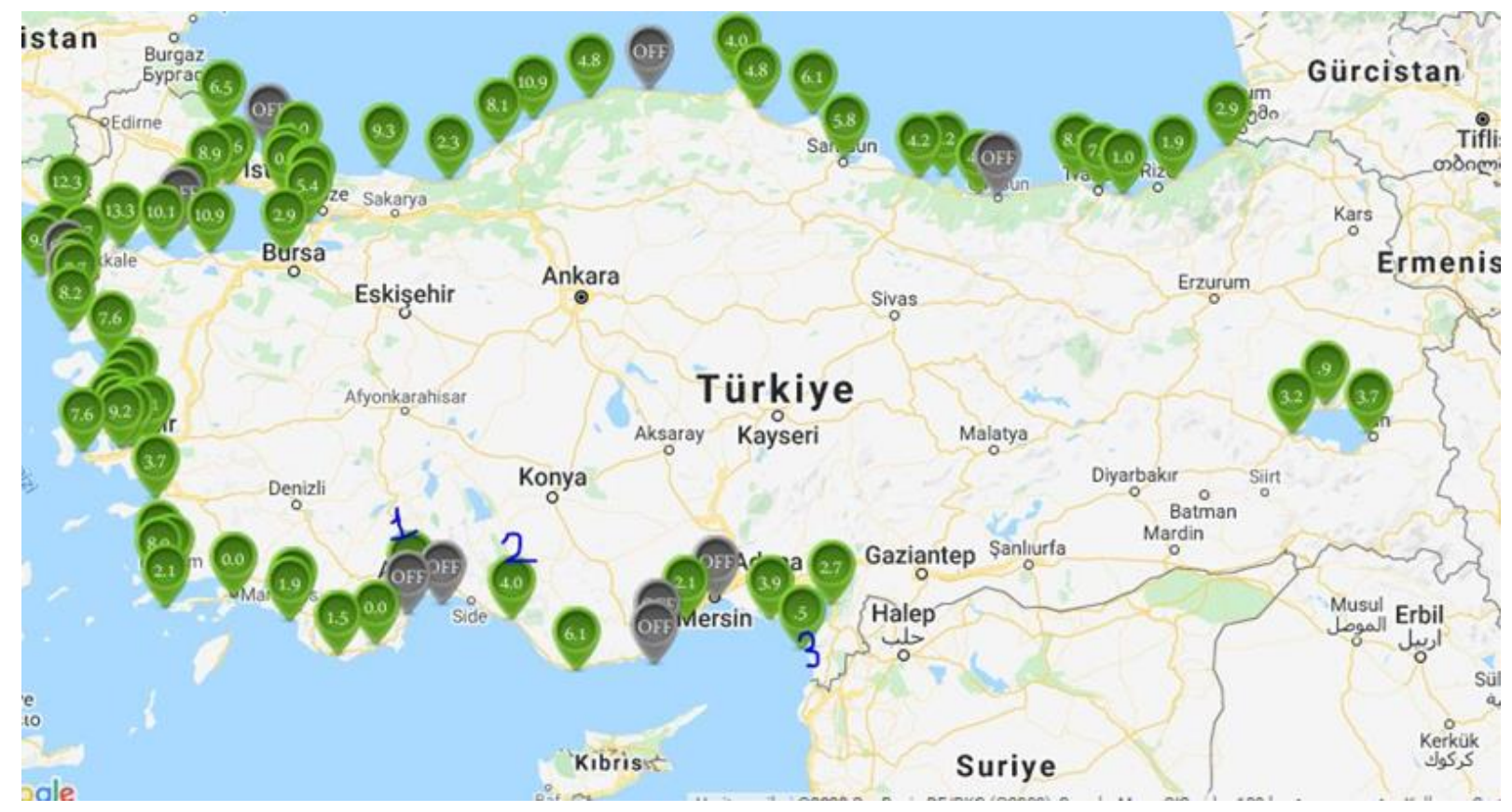

Şekil 3. Meteoroloji istasyonlarının konumları (Sırasıyla 1, 2 ve 3 numaralı istasyonlarda Konyaaltı, Alanya, ve Samandağ gösterilmektedir)

Tablo 1: İstasyonlara ait rüzgar hızı ve yoğunluğu

\begin{tabular}{lll}
\hline istasyon & Rüzgar hızı $(\mathrm{m} / \mathrm{s})$ & Rüzgar hızı yoğunluğu $(\mathrm{W} / \mathrm{m} 2)$ \\
\hline Konyaalti/1 & 3.54 & 111 \\
\hline Alanya/2 & 6.88 & 441 \\
\hline Samandag/3 & 6.61 & 418 \\
\hline
\end{tabular}

Tablo 2 :100 metrede rüzgar hızı ve yoğunluğu

\begin{tabular}{llll}
\hline istasyon & Rüzgar hızı $(\mathrm{m} / \mathrm{s})$ & Güç yoğunluğu $(\mathrm{W} / \mathrm{m} 2)$ & $100 \mathrm{~m}$ rüzgar hızı $(\mathrm{m} / \mathrm{s})$ \\
\hline Konyaaliti/1 & 3.54 & 111 & 4.01 \\
\hline Alanya/2 & 6.88 & 441 & 8.62 \\
\hline Samandag/3 & 6.61 & 418 & 8.48 \\
\hline
\end{tabular}

Tablo 2'de Alanya'nın 8,62 m / s rüzgâr hızı ve 100 metrede $441 \mathrm{~W} / \mathrm{m} 2$ güç yoğunluğu ile en iyi lokasyon olduğu görülmektedir. Samandağ lokasyonunun sonuçları $(8.48 \mathrm{~m} / \mathrm{s}$ rüzgâr hızı ve 100 metrede $418 \mathrm{~W} / \mathrm{m} 2$ güç yoğunluğu) Alanya lokasyonuna çok yakındır. Bu çalışmanın amacı bölgesel sera gazı emisyonlarını en aza indirmek olduğundan, yoğun termik santral faaliyetlerinin olduğu Samandağ lokasyonu ADRS kurulumu için seçilmiştir. Rüzgâr hızı ve rüzgâr enerjisi yoğunluğu değerlerine göre V117-4,2 MW, MHI Vestas adlı açık deniz rüzgâr türbini, Samandağ konumunda (Adım 2) (MHI, 2020) önerilen ADRS için kullanılabilir. Samandağ sahilinde deniz derinliği 20-50 metreye ulaştığı için (MHI, 2020) bu verilere göre ADRS için Veritas (2014) 'de verilen referansta belirtilen temel yapılarından tripod temel yapısı seçilmiştir. Ardından rüzgâr türbininin yerleştirilmesine başlanır. Türbin yerleşiminde, türbinler arasındaki mesafe dikey eksende 8D10D, yatay eksende 2D-5D olmalıdır ( $\mathrm{D}=$ Rotor çap1) (Gasch ve Joche 2012). Bu lokasyonda 4,2 MW türbinler arasındaki mesafe yatay eksende 4D, dikey eksende 8D olarak seçilmiştir. Rüzgâr türbinleri arasında seçilen mesafeye bağlı olarak $(4,2 * 76=$ 319,2 MW) ilgili konuma toplam 4,2 MW gücünde 76 rüzgâr türbini yerleştirilebilir. 319,2 MW Kurulu güce sahip ADRS'nin konumu Şekil 4'te gösterildiği gibidir. 


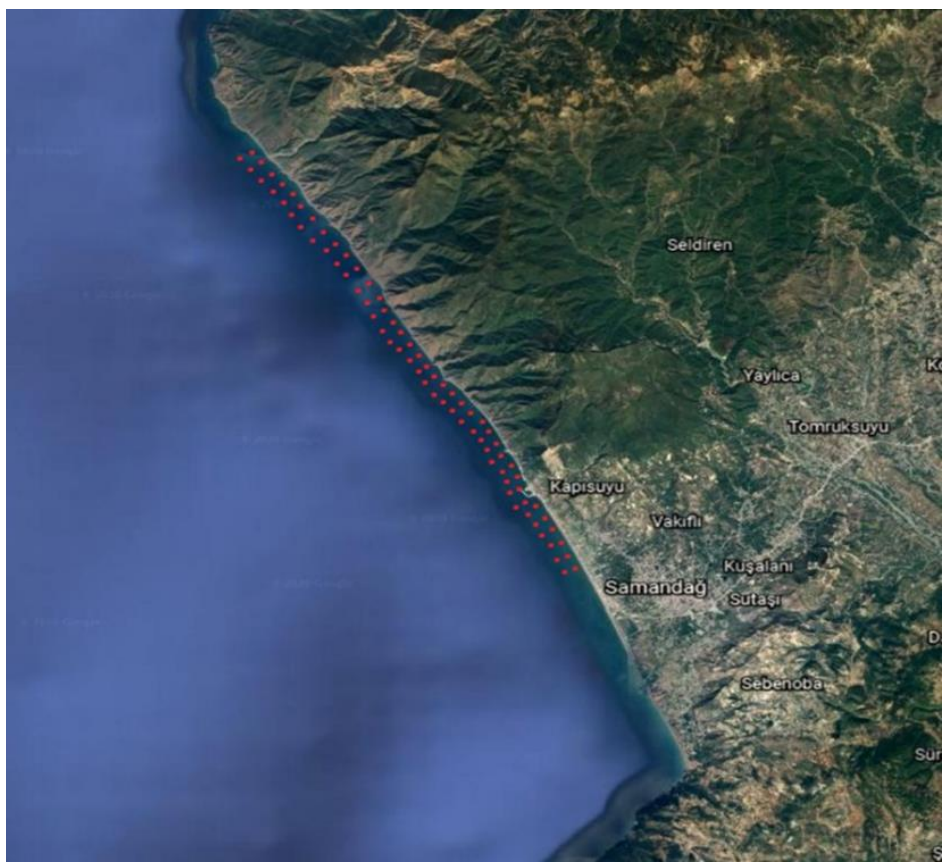

Şekil 4. Açık deniz rüzgâr türbini yerleştirme alanı (Samandağ'a lokasyonu)

\subsection{ADRS ile bölgesel iletim sisteminin modellenmesi}

Bu çalışmada, Akdeniz bölgesi 9 bara $380 \mathrm{kV}$ iletim sisteminin yaklaşı modeli ve bu iletim sistemine entegre edilecek ADRS'nin sanal modeli DigSilent Power Factory yazılımı kullanılarak modellenmiştir. Bu iletim sistemi 5 jeneratör ve 10 iletim hattından oluştuğu kurgulanmıştır. Bu iletim sisteminin tek hat şeması Şekil 5'de verildiği gibidir. Toplam yük talebinin aktif güç 2045 MW ve reaktif güç 64,8 MVAR olduğu bu iletim sistemi modelinde, Erzin (PG3) ve Sub3 (PG4) veriyollarındaki jeneratörler fosil bazlı (kömüre dayalı) termik santrallerdir. Samandagi (PG6) otobüsündeki jeneratör ADRS'dir. Bu iletim sisteminin yük ve jeneratör verileri Tablo 3 'te, hat parametreleri Tablo 4'te verilmiştir. $\mathrm{Bu}$ modellenmiş iletim sisteminde ADRS'nin bölge iletim sistemine entegrasyonu yaklaş1k 20 km'lik bir iletim hattı ile sağlanmıştır.

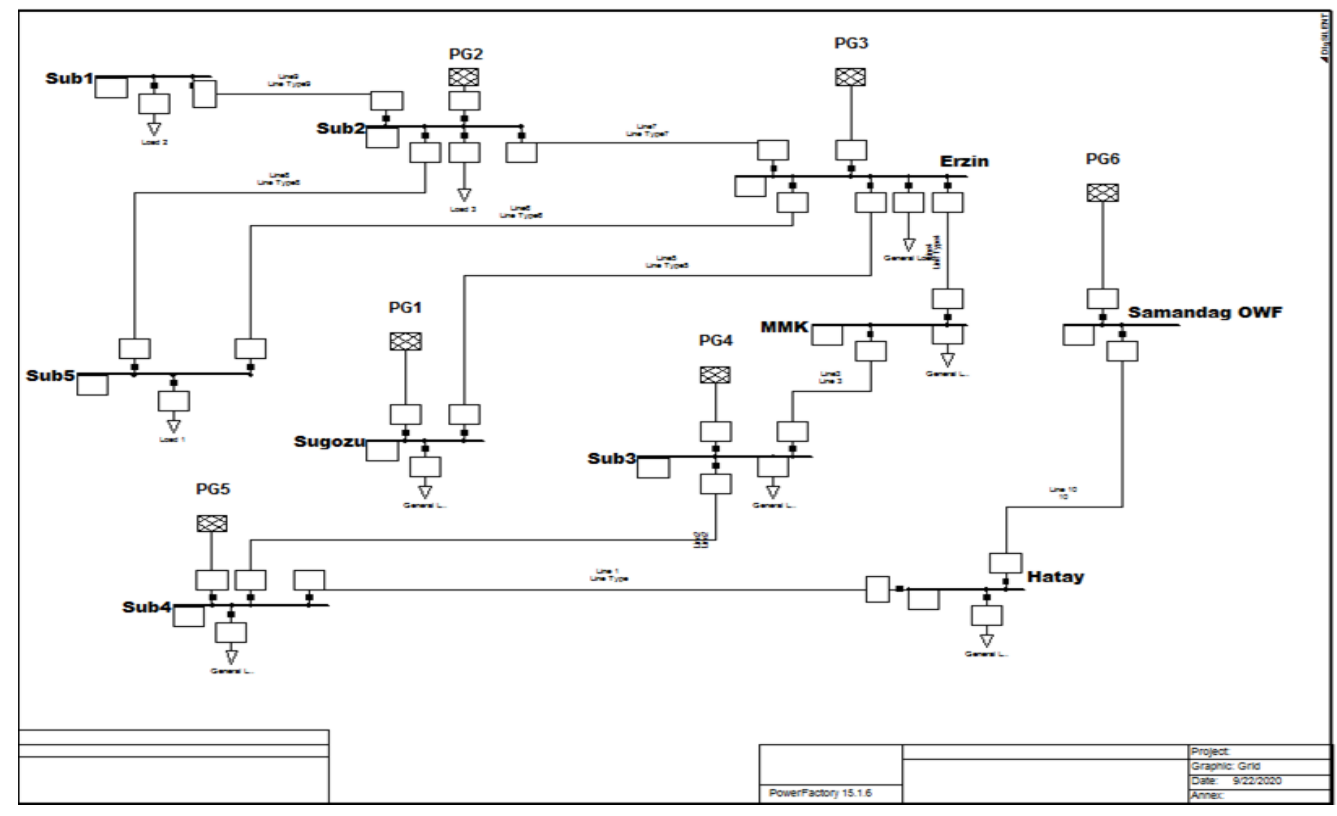

Şekil 5. 9 bara $380 \mathrm{kV}$ Akdeniz tek hatlı iletim sistemi modeli 
Avrupa Bilim ve Teknoloji Dergisi

Table 3. İletim sistemine ait hat verileri

\begin{tabular}{lllll}
\hline $\mathbf{N l}$ & $\mathbf{N r}$ & $\mathbf{R}(\mathbf{p u})$ & $\mathbf{X}(\mathbf{p u})$ & $\mathbf{B} / \mathbf{2}(\mathbf{p u})$ \\
\hline Sub1 & Sub2 & 0.00075282 & 0.011254 & 0.385 \\
\hline Sub2 & Sub5 & 0.00018656 & 0.0017738 & 0.06079 \\
\hline Sub2 & Erzin & 0.00032161 & 0.0038276 & 0.116694 \\
\hline Sugozu & Erzin & 0.00043986 & 0.005053 & 0.165431 \\
\hline Erzin & MMK & 0.00059276 & 0.0068098 & 0.222934 \\
\hline MMK & Sub3 & 0.00020297 & 0.0030344 & 0.10399 \\
\hline Sub3 & Sub4 & 0.00028945 & 0.0026747 & 0.059194 \\
\hline Sub4 & Hatay & 0.000194978 & 0.00291484 & 0.09989 \\
\hline Sub5 & Erzin & 0.0001608 & 0.0018908 & 0.0583474 \\
\hline Hatay & Samandag & 0.00024163 & 0.0036124 & 0.12379 \\
\hline
\end{tabular}

Tablo 4. İletim istemine ait yük ve üretim verileri

\begin{tabular}{|c|c|c|c|c|c|c|c|}
\hline & & \multicolumn{2}{|c|}{ Yük } & \multirow{2}{*}{$\begin{array}{c}\text { Jeneratör } \\
\text { Pmin (MW) }\end{array}$} & \multirow{2}{*}{$\begin{array}{c}\text { jen } \\
\text { Pmax (MW) }\end{array}$} & \multirow{2}{*}{$\begin{array}{c}\text { jen } \\
\text { Qmin } \\
\text { (MVAR) }\end{array}$} & \multirow{2}{*}{$\begin{array}{c}\text { jen } \\
\text { Qmax } \\
\text { (MVAR) }\end{array}$} \\
\hline Bara no & $\begin{array}{c}\text { Bara } \\
\text { kod }\end{array}$ & P (MW) & Q (MVAR) & & & & \\
\hline Sub1 & 0 & 500 & 10 & - & - & - & - \\
\hline $\operatorname{Sub} 2\left(\mathrm{P}_{\mathrm{G} 2}\right)$ & 2 & 250 & 5.8 & 100 & 290 & -50 & 15 \\
\hline Sub5 & 0 & 315 & 10 & - & - & - & - \\
\hline $\operatorname{Erzin}\left(\mathrm{P}_{\mathrm{G} 3}\right)$ & 2 & 270 & 8 & 300 & 425 & -30 & 15 \\
\hline $\operatorname{Sugozu}\left(\mathrm{P}_{\mathrm{G} 1}\right)$ & 2 & 250 & 4 & 120 & 250 & -20 & 20 \\
\hline MMK & 0 & 85 & 10 & - & - & - & - \\
\hline $\operatorname{Sub3}\left(\mathrm{P}_{\mathrm{G} 4}\right)$ & 1 & 25 & 8 & 395 & 985 & -20 & 25 \\
\hline Sub4 $\left(\mathrm{P}_{\mathrm{G} 5}\right)$ & 2 & 150 & 5 & 350 & 465 & -20 & 15 \\
\hline Hatay & 0 & 200 & 4 & - & - & - & - \\
\hline Samandag $\left(\mathrm{P}_{\mathrm{G} 6}\right)$ & 2 & 0 & 0 & 310 & 319.2 & -25 & 15 \\
\hline
\end{tabular}

Bara kod 1= slak, $2=$ üretim, $0=$ tüketim baras 1

\subsection{Güç sisteminin analizi}

$\mathrm{Bu}$ çalışmada gerçek güç sistemine uygun olarak Newton Raphson metodu ile yük akış analizi yapılmıştır. DigSilent programinda modellenen bölgesel enerji iletim sisteminde, ADRS'nin ana şebekeye bağlı olup olmadığına göre yük akış analizi yapılmıştır (Adım 3). Newton-Rapson yöntemine göre yapılan yük akış analizinden elde edilen sonuçlar Tablo 5 'te verilmiştir.

Tablo 5'te, ADRS ana şebekeye bağlı olmadığında, PG3 fosil yakıt bazlı santral 335 MW aktif güç / 15 MVAR reaktif güç, PG4 fosil yakıt bazlı santral $995 \mathrm{MW}$ aktif güç / 11,4 MVAR reaktif güç üretmiştir. $\mathrm{Bu}$ durumda güç sisteminde 10 MW aktif güç kayıpları / -9,4 MVAR reaktif güç kayıpları hesaplanır. ADRS ana şebekeye bağlandığında PG3 335 MW aktif güç / 15 MVAR reaktif güç- PG4 jeneratör 676,1 MW aktif güç / -2,5 MVAR reaktif güç üretir. PG6 jeneratör 319,2 MW aktif güç / 5 MVAR reaktif güç üretmektedir. ADRS ana şebekeye bağlandığında, aktif güç kaybı 10,32 MW aktif güç / -
18,3 MVAR reaktif güç kaybı olarak hesaplanır. Güç sistemlerinde zehirli gaz ve sera gazı emisyonları fosil bazlı üretimin ürettiği saatlik aktif güce (MWH / ton) göre tahmin edilebilir. Örnek güç sisteminde Erzin (PG3) ve Sub3 (PG4) baralrda bulunan termik santralin saatlik tahmini emisyon katsayıları Tablo 6'da verilmiştir. Bu çalışmada, ADRS ana şebekeye bağlandığında, salınım barasındaki (Sub3-PG4) fosil yakıt bazlı elektrik santralinin aktif güç üretimini azaltmaktadır. Erzin ve Sub3 otobüslerinde fosil bazlı jeneratörün toplam toksik gaz ve yakıt emisyonu Denklem 2 ile hesaplanır. ADRS ana şebekeye bağlandığında yapılan yük akış analizinde Sub3 barası üzerindeki termik santralin atmosfere salınan gazın toplam emisyonu 1,4 ton / saat (SOx için) 0,004 ton / saat (NOx için) ve 281.415 ton / saat (COx için) azalır. Böylece, bu simülasyon modelinde, bu bölgede atmosfere salınan toplam emisyonlar, bir yıl içerisinde yaklaşık 12264 ton toksik gaz (SOx, NOx) ve 2,46 milyon ton sera gaz1 (COx) azalt1labilmektedir. 
European Journal of Science and Technology

Table 5: Yük akış analiz sonuçları (Newton Raphson)

\begin{tabular}{|c|c|c|c|c|c|c|c|}
\hline \multicolumn{4}{|c|}{ ADRS ana şebekeye bağlı değil iken } & \multicolumn{4}{|c|}{ ADRS bağlı } \\
\hline $\mathrm{P}_{\mathrm{G} 1}$ & $150 \mathrm{MW}$ & Sub1 & $0.99 \mathrm{pu}$ & $\mathrm{P}_{\mathrm{G} 1}$ & $150 \mathrm{MW}$ & Sub1 & $0.99 \mathrm{pu}$ \\
\hline $\mathrm{P}_{\mathrm{G} 2}$ & $120 \mathrm{MW}$ & Sub2 & $0.99 \mathrm{pu}$ & $\mathrm{P}_{\mathrm{G} 2}$ & $120 \mathrm{MW}$ & Sub2 & $0.99 \mathrm{pu}$ \\
\hline $\mathrm{P}_{\mathrm{G} 3}$ & $335 \mathrm{MW}$ & Sub5 & $0.99 \mathrm{pu}$ & $\mathrm{P}_{\mathrm{G} 3}$ & $335 \mathrm{MW}$ & Sub5 & $0.99 \mathrm{pu}$ \\
\hline $\mathrm{P}_{\mathrm{G} 4}$ & $995 \mathrm{MW}$ & Erzin & $0.99 \mathrm{pu}$ & $\mathrm{P}_{\mathrm{G} 4}$ & $676.1 \mathrm{MW}$ & Erzin & $0.99 \mathrm{pu}$ \\
\hline $\mathrm{P}_{\mathrm{G} 5}$ & $455 \mathrm{MW}$ & Sugozu & $0.99 \mathrm{pu}$ & $\mathrm{P}_{\mathrm{G} 5}$ & $455 \mathrm{MW}$ & Sugozu & $0.99 \mathrm{pu}$ \\
\hline $\mathrm{P}_{\mathrm{G} 6}$ & - & MMK & $1 \mathrm{pu}$ & $\mathrm{P}_{\mathrm{G} 6}$ & $319.2 \mathrm{MW}$ & MMK & $1 \mathrm{pu}$ \\
\hline $\mathrm{Q}_{\mathrm{G} 1}$ & $10 \mathrm{MVAR}$ & Sub3 & $1 \mathrm{pu}$ & $\mathrm{Q}_{\mathrm{G} 1}$ & $10 \mathrm{MVAR}$ & Sub3 & $1 \mathrm{pu}$ \\
\hline $\mathrm{Q}_{\mathrm{G} 2}$ & 11 MVAR & Sub4 & $1 \mathrm{pu}$ & $\mathrm{Q}_{\mathrm{G} 2}$ & $11 \mathrm{MVAR}$ & Sub4 & $1 \mathrm{pu}$ \\
\hline $\mathrm{Q}_{\mathrm{G} 3}$ & 15 MVAR & Hatay & $1 \mathrm{pu}$ & $\mathrm{Q}_{\mathrm{G} 3}$ & 15 MVAR & Hatay & $1.01 \mathrm{pu}$ \\
\hline $\mathrm{Q}_{\mathrm{G} 4}$ & 11.4 MVAR & Samandagi OWF & - & $\mathrm{Q}_{\mathrm{G} 4}$ & $-2.5 \mathrm{MVAR}$ & Samandagi OWF & $1.01 \mathrm{pu}$ \\
\hline $\mathrm{Q}_{\mathrm{G} 5}$ & $8 \mathrm{MVAR}$ & $\mathrm{SO}_{\mathrm{x}(\text { sum })}$ & $2.949(\operatorname{ton} / \mathrm{s})$ & $\mathrm{Q}_{\mathrm{G} 5}$ & $8 \mathrm{MVAR}$ & $\mathrm{SO}_{\mathrm{x}(\mathrm{sum})}$ & $1.549(\operatorname{ton} / \mathrm{s})$ \\
\hline $\mathrm{Q}_{\mathrm{G} 6}$ & - & $\mathrm{NO}_{\mathrm{x}(\mathrm{sum})}$ & $0.0438($ ton/s) & $\mathrm{Q}_{\mathrm{G} 6}$ & $5 \mathrm{MVAR}$ & $\mathrm{NO}_{\mathrm{x}(\mathrm{sum})}$ & 0.0398 (ton/s) \\
\hline $\mathrm{Q}_{\text {loss }}$ & -9.4 MVAR & $\mathrm{CO}_{2 \text { (sum) }}$ & $1177.40(\operatorname{ton} / \mathrm{s})$ & $\mathrm{Q}_{\text {loss }}$ & -18.3 MVAR & $\mathrm{CO}_{2 \text { (sum) }}$ & $895.99($ ton/s) \\
\hline $\mathrm{P}_{\text {loss }}$ & $10 \mathrm{MW}$ & & & $\mathrm{P}_{\text {loss }}$ & $10.32 \mathrm{MW}$ & & \\
\hline
\end{tabular}

Table 6 : Sırasıyla PG3 ve PG4 baralarında kömüre dayalı termik santrallerin tahmini emisyon katsayıları

\begin{tabular}{cccccc}
\hline $\boldsymbol{a}_{\boldsymbol{i}}$ & $\boldsymbol{\beta}_{\boldsymbol{i}}$ & $\boldsymbol{\gamma}_{\boldsymbol{i}}$ & $\xi_{\boldsymbol{i}}$ & $\boldsymbol{\lambda}_{\boldsymbol{i}}$ & $£_{\boldsymbol{i}}$ \\
\hline 0.004 & -0.0074 & 0.00028 & 0.015 & 0.00052 & 0.892 \\
\hline 0.0039 & -0.00735 & 0.000277 & 0.0154 & 0.00054 & 0.883 \\
\hline
\end{tabular}

\section{Sonuç}

$\mathrm{Bu}$ makalede, Akdeniz bölgesi için açık deniz rüzgâr enerjisi potansiyeli değerlendirmesi, bu bölgede yeni bir açık deniz rüzgâr çiftliği kurulma aşaması ve zehirli / sera gazı emisyonlarının azaltımı incelenmektedir. Bu çalışmada, Akdeniz Bölgesi'nde değerlendirelen lokasyonlarda yapılan analize göre, bölgedeki yoğun termik santral aktivitesi nedeniyle $(418 \mathrm{~W} / \mathrm{m} 2$ rüzgâr gücü yoğunluğu ve 8.48 m / s 100 metre yükseklik rüzgâr hızına sahip) Samandağ lokasyonu uygun alan olarak belirlendi. Bu lokasyonda 319,2 MW kurulu güce sahip ADRS kurulacağ belirlendi. Ardından, önerilen ADRS ve bölgesel iletim sistemi modellenmiştir. $\mathrm{Bu}$ güç sistemi modelinde, termik santralin yıllık / saatlik emisyon miktarının bölgesel olarak azaltılması yük akış analizi kullanılarak hesaplanmıştır. Bu yazıda Newton Raphson yöntemine göre yapılan yük akışında ADRS ana şebekeye bağlandığında bölgedeki fosil bazlı termik santrallerin $\mathrm{CO} 2$ emisyonu 10,31 milyon tondan 7,84 milyon tona düşürebileceği tespit edilmiştir ( bir yıl içinde).

\section{Kaynakça}

Akdağ, O., \& Yeroglu, C. (2020). An evaluation of an offshore energy installation for the Black Sea region of Turkey and the effects on a regional decrease in greenhouse gas emissions. Greenhouse Gases: Science and Technology, 10(3), 531-544.

Akyuz, Y., and Atis, E. 2016. Türkiye'de İklim Değişikliği Tarım Etkileşiminin İki Yönüyle İncelenmesi. Uluslararası Katılıml, 2:08-09.

e-ISSN: 2148-2683
Argin, M., and V. Yerci. 2017. Offshore wind power potential of the Black Sea region in Turkey. International Journal of Green

Energy 14(10):811-818. doi:10.1080/15435075.2017.1331443.

Argin, M., V. Yerci. 2017. Offshore wind power potential of the Black Sea region in Turkey. International Journal of Green Energy 14(10): 811-818. doi: /doi.org/10.1080/15435075.2017.1331443.

Arrhenius, S. 1896. XXXI. On the influence of carbonic acid in the air upon the temperature of the ground. The London, Edinburgh, and Dublin Philosophical Magazine and Journal of Science 41(251):237-276.

Bal, H. 2019. Analysing of agricultural greenhouse gas emissions based on the environmental kuznets curve approach for oecd countries: Master Thesis, Eskişehir Osmangazi University.

Benavides, P. T., Lee, U., Zarè-Mehrjerdi, O. 2020. Life cycle greenhouse gas emissions and energy use of polylactic acid, bio-derived polyethylene, and fossil-derived polyethylene. Journal of Cleaner Production 277, 124010.

Bilgili, M., A.Yasar, E. Simsek. 2011. Offshore wind power development in Europe and its comparison with onshore counterpart. Renewable and Sustainable Energy Reviews. 15(2):(2011) 905-915.

Cali U., N. Erdogan, S. Kucuksari and M. Argin. 2018. Technoeconomic analysis of high potential offshore wind farm locations in Turkey. Energy strategy reviews 22:325-336.

Erdogdu, E. 2010. Turkish support to Kyoto Protocol: A reality or just an illusion. Renewable and Sustainable Energy 
Reviews 14(3):1111-1117.

doi: doi.org/10.1016/j.rser.2009.10.020Get rights and content.

Fleming, J. R. 1999. Joseph Fourier, the 'greenhouse effect', and the quest for a universal theory of terrestrial temperatures. Endeavour 23(2):72-75.

Gasch, R., T. Joche. 2012. Wind Power Plants: Fundamentals, Design, Construction and Operation, Second Edition. Springer Publication.

International Energy Agency. 2018. Global Energy \& CO2 Status Report 2018. https://www.iea.org/geco/emissions/.

Marina. 2019. Republic of Turkey Turkish naval forces command office of navigation, hydrography and oceanography 2019. http://www.shodb.gov.tr/shodb_esas/index.php/en/.

Melikoglu, M. 2013. Vision 2023: Feasibility analysis of Turkey's renewable energy projection. Renewable Energy 50:570-575. doi: 10.1016/j.renene.2012.07.032.

MHI. 2020. https://www.vestas.com/en/products/4-mwplatform/v117.

Mohsenipour, M., Ebadollahi, M., Rostamzadeh, H., \& Amidpour, M. 2020. Design and evaluation of a solar-based trigeneration system for a nearly zero energy greenhouse in arid region. Journal of Cleaner Production 254, 119990.
Ozes, R., and S. Cagatay. 2019. Sera gazı azaltımı için alternatif karbon vergisi uygulamaları etki analizi: 2018 y1l için bulgular. METU Studies in Development 45(3):255-283.

Teias. 2020. Turkish Government Electricity Transmission Company, Turkish Government Electricity Transmission Company Annual Report 2020. Annual Report. https://www.teias.gov.tr/sites/default/files/201904/kurulu_guc_2019.pdf/.

Turkish State Meteorological Service. 2019. Marine Automatic Observation Stations. https://www.mgm.gov.tr/deniz/denizomgi.aspx/.

Veritas. 2014. Stiftelsen Det Norske Veritas (DNV). Design of Offshore Wind Turbine Structures.

Wang, S., Wang, S., \& Liu, J. (2019). Life-cycle green-house gas emissions of onshore and offshore wind turbines. Journal of Cleaner Production, 210, 804-810.

Wind Map. 2019. Republic of Turkey Ministry of Energy and Natural Resources. Turkey wind map. http://www.yegm.gov.tr/YEKrepa/REPA-duyuru_01.html.

WWEA. 2019. World Wind Energy Association 2019. https://wwindea.org/ 